\title{
FENOMENOLOGÍA
}

\section{¡LA BARRERA DEL CUIDADO! RELATO DE UNA EXPERIENCIA DE ENFERMAR}

\author{
-José Manuel Tordera Alba.
}

Diplomado en Enfermería. Licenciado en Ciencias de la Educación -M $M^{a}$ Teresa Rodríguez Avilés. Pediatra

C/ Antonio Gaudí 9, 2 ${ }^{\circ}$, San Juan Despí. Barcelona 08970

TI 933731425

e-mail: jose.tordera@retemail.es

977251411

\section{RESUMEN}

\section{¿LA BARRERA DEL CUIDADO! RELATO} DE UNA EXPERIENCIA DE ENFERMAR

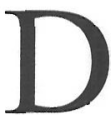
ice el dicho popular "no hables del perro hasta que no pases del cortijo", y en nuestra experiencia es totalmente válido; presentamos un relato que pretende contar lo que ha significado en la experiencia de los autores (matrimonio; enfermero él y pediatra ella) el paso por una enfermedad grave familiar (Linfoma de Hodgkin más autotransplante) y de cómo se ven diferentes las cosas según estés colocado en el lado de la barrera que es la salud y la profesión (lo uno), o en de la enfermedad (lo otro).

\section{THE CARING BARRIER! STORY OF AN EXPERIENCE OF ILLNESS}

s a popular saying goes "don't count your
eggs until they are hatched" in our expe-
rience this is absolutely true. We are presenting a story that tells what a serious illness (Hodgkin limphoma plus self-transplant) has meant for the authors (a married couple, he being a nurse and she a pediatrician) and how things are seen in a different way depending on which side of the barried you look at them from, health and the profession (one) or illness (the other).
La vida es una continua resistencia al vacío de la muerte. Vivir es resistir. Si lo otro de la vida es la muerte, cada fragmento de vida es una pequeña batalla ganada a la muerte........ Vencemos la muerte del niño que fuimos, de las relaciones que ya no son, de la lozanía, de la belleza, de la plenitud. El negativo de mi vida son todas mis muertes.

Michel Foucault (1926-1984)

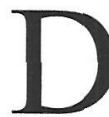
icen que la vida es eso que te pasa mientras haces planes para otra cosa. Nos gusta hacer planes; nos dan la sensación de control sobre nuestras vidas. Estaban acostumbrados a ver los toros desde la barrera'. La barrera parece darte cierta seguridad en lo que haces. Hay muchos tipos de barrera: barreras físicas, ideológicas, morales, intelectuales, psicológicas, espacio-temporales, etc. En este caso, esa barrera se llama profesión, ella es médico, él es enfermero.

Ella y él tienen una profesión parecida, sólo parecida. Aunque cada uno ve al paciente desde un punto de vista distinto, la función de la barrera es la misma: el proporcionar ese lugar privilegiado desde el cual se interpreta lo que le pasa a la per- 
sona y de qué manera se puede intervenir en su ayuda. Dos barreras distintas para un mismo fin. Así, la profesión es el punto de vista desde el cual ves lo que pasa y te faculta para tomar decisiones acerca del paciente que demanda tus servicios.

En este lado de la barrera (etic), en -lo uno-, la enfermedad y sobre todo la enfermedad grave, era algo que pasaba al otro lado y a otras personas, y la barrera, el criterio a través del cual se da más importancia a unas cosas que a otras en ese proceso.

A este lado de la barrera, en el lado de lo uno, las cosas se ven al modo de grano gordo; se escapan los pequeños detalles, dado que no parecen tener influencia definitiva en la resolución de la patología, lo importante es el bulto del problema.

Al otro lado de la barrera (emic) hay -en este caso- enfermedad -lo otro-, y también miedo, inseguridad e impotencia. Cuando estás en el lado de lo otro las cosas se ven al modo de grano fino; aquí cuentan los detalles, se vuelven importantes las caras, las expresiones, las maneras y el tacto. No es lo mismo estar a uno o a otro lado de la barrera, es cualitativamente diferente; en lo otro las actitudes adquieren una significación impensable desde el otro lado de la barrera.

Vivimos en un mundo percibido como dual. Así como la analgesia, el día, la verdad, no tienen sentido si no es por la existencia del dolor, la noche, la mentira, lo uno no tiene sentido si no es por la existencia de lo otro.

Pero en la realidad no hay distinciones tan claras entre lo verdadero y lo falso, el día y la noche no es de día y un segundo después ya es de noche sino que la transición de lo uno a lo otro es gradual, borrosa, poco clara-. Nuestra mente necesita clasificar las cosas de esa manera tan simplista para poder tomar decisiones, hemos heredado de Aristóteles que las cosas son: A o No A, pero en realidad es: A y No A, a la vez.

Por azar, ella pasó al lado de lo otro, y el se aferraba a este lado, al lado conocido de la barrera. Así, los puntos de vista no coincidían, no eran lo mismo. Dice el dicho popular que la experiencia es la madre de la ciencia y debería añadírsele: y de la conciencia. Por la experiencia no sólo se aprenden conocimientos, sino también, y aun siendo inconscientes de ello, actitudes y valores. La experiencia de pasar de un lado al otro de la barrera provoca aprendizaje.

El toro de lo otro se ve muy bien desde este lado de la barrera. Pero cuando estás en su lado, y si el toro es de la ganadería de los Linfomas, deja de ser un toro para convertirse en una manada de elefantes entrando a saco en una tienda de porcelanas. Entonces, aún resaltan más las diferencias entre lo uno y lo otro, entre la ciencia y la conciencia. Cuando te está pasando por encima una apisonadora física y moral, los planes pierden importancia y lo uno, la salud, eso que sólo admitimos como lo más importante el día 22 de diciembre de cada año, realmente se convierte en el único objetivo.

Te sientes perdido. La barrera ya no vale como punto de vista, pues no puedes mantener cierta distancia respecto a los acontecimientos, formas parte de ellos y no te dejan pensar claramente. Es una sensación extraña, no se puede contar con palabras. Las mismas palabras significan diferentes cosas para distintas personas, así que sólo quedan las percepciones y las actitudes. Por el mismo motivo, tampoco sirven de mucho las palabras de quien te está ayudando a pasar de lo otro a lo uno, sólo quedan las actitudes. Desde lo otro, la actitud de quien está en el lado de lo uno es la única cornisa donde agarrarse. Al espíritu, a la conciencia, sólo se llega por la emoción, no por la razón; no valen las palabras de ánimo, y es más, en ese momento las palabras de ánimo suenan como una falta de sensibilidad, como una descortesía, casi como un insulto, "es que no me puedo animar, para eso tendría que tener algo de fuerza y no la tengo, ¿es que no se dan cuenta?" -decía ella-. De eso, quienes les han cuidado saben un rato largo, han invertido en ellos un capital emocional que no cabe en el Banco Central

La vida es eso que te pasa (por azar) mientras haces planes para otra cosa. Parece que todo dependa del azar, le echamos la culpa -te ha tocado- pero también creemos en él, si no, no existirían las loterías. Ahora bien, hay una lotería que preferimos que no nos toque, como la que te pone del lado de lo otro; pero el azar en sí no existe (esto suena a herejía matemática, pero así es percibido por ambos). Llamamos azar a lo que es puro desconocimiento del devenir. ¡Bendita sea la ignoran- 
cia!. De saber cuál sería nuestro futuro, la vida perdería el sentido y también los planes que el azar trunca.

Superaron la enfermedad gracias a la bendición de Dios que supone la capacidad inteligente del ser humano para utilizarla en su propio beneficio.

Ahora vuelven a hacer planes. Planificar es suponer que se puede asumir el cambio, y se trata de cambiar para mejorar. Que no pase como a aquél que decía: "ya he cambiado: antes no fumaba y ahora ya fumo".

Vuelven a estar del lado de lo uno, y es de esperar que esta unidad dure mucho tiempo, pues no es agradable la otridad ${ }^{2}$.

Ahora, sus barreras, la de él y la de ella, tienen una permeabilidad a lo afectivo que antes no tenían; antes, la involucración afectiva con el paciente era símbolo de falta de profesionalidad, de falta de rigor; ahora es otra cosa, saben por propia experiencia que la frase "Venga, anímate, amigo" no vale, y que lo que da un poco de paz al espíritu del que sufre es algo parecido a: "Qué fuerte es lo que te está pasando. Llámame cuando quieras que estaré a tu lado". Ahora entienden que la manera como se hacen y dicen las cosas es más importante que las cosas mismas que estás haciendo o diciendo; lo importante no es tanto la acción en sí, sino el significado que va asociado a ella. Lo que importa no es la palabra en sí, sino lo que significa la actitud de quien la pronuncia. Ahora pueden estar más tiempo con el enfermo sin decir nada; sólo estar, sin el prurito de tenerlo todo controlado porque la profesionalidad así lo exige, sin sentirse como un pulpo en un garaje.

El olvido, esa especie de amnesia selectiva, es otra bendición de Dios.

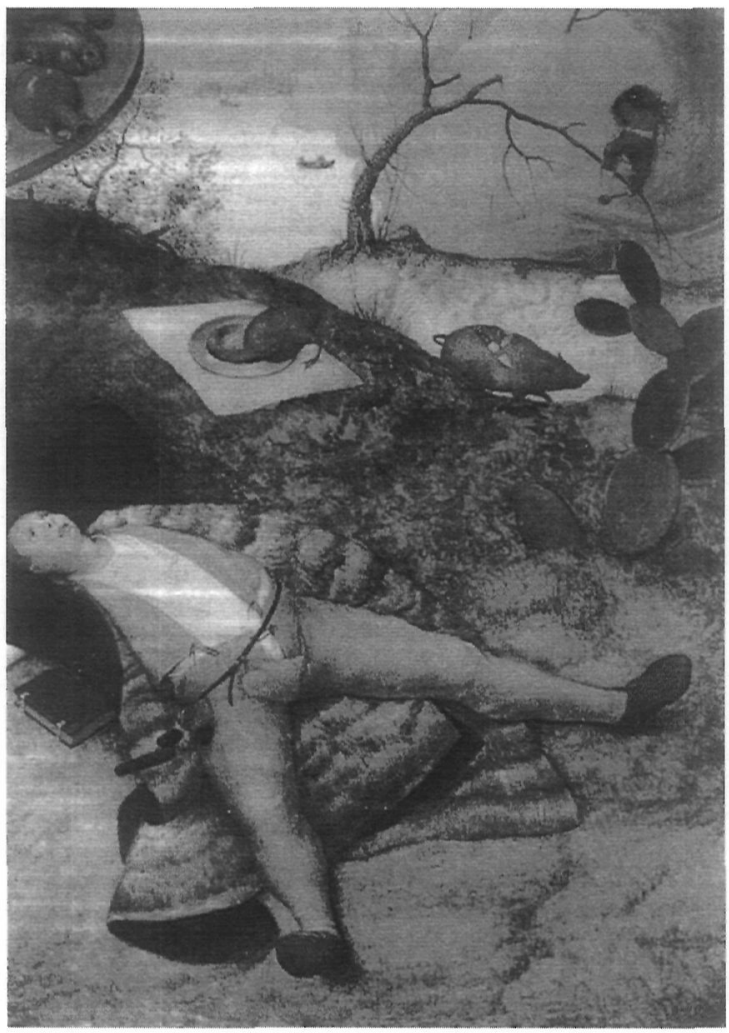

